\title{
TRABALHO E FORMAÇÃO DOS EDUCADORES DE CRECHE EM BOTUCATU: REFLEXÕES CRÍTICAS
}

\author{
CLAUDIA FERNANDES VOLPATO \\ Faculdade de Filosofia e Ciências da Universidade Estadual Paulista - Marília/SP \\ claudiavolpato64@yahoo.com.br \\ SUELY AMARAL MELLO \\ Faculdade de Filosofia e Ciências da Universidade Estadual Paulista - Marília/SP \\ suepedro@terra.com.br
}

\begin{abstract}
RESUMO
Considerando a recente preocupação de estabelecer programas de formação em serviço para educadores de creche, estudamos oito creches municipais de Botucatu (SP). O objetivo foi conhecer as condiçôes de trabalho e de formação dos educadores com base em dados que permitissem avaliar os procedimentos de educação inicial e continuada a que foram submetidos, as concepçôes subjacentes à sua prática profissional, suas expectativas sobre os programas de formação em serviço, assim como as efetivas necessidades a que esses programas precisam responder em vista dos parâmetros de qualidade estabelecidos para a educação infantil. A partir dos resultados obtidos, traçamos um panorama e esboçamos sugestões que possam subsidiar uma proposta de formação inicial e continuada para esses educadores, valendo-nos de algumas contribuições da teoria histórico-cultural enriquecidas com reflexões críticas e recentes na área, e do contraponto com as propostas defendidas por documentos oficiais em vigor propalados nacionalmente.

CRECHES - FORMAÇÃO PROFISSIONAL - BOTUCATU-SP - PROFISSIONAIS DE EDUCAÇÃO INFANTIL
\end{abstract}

\section{ABSTRACT}

WORK AND EDUCATION OF DAY CARE CENTER EDUCATORS IN BOTUCATU: CRITICAL REFLECTIONS. Considering the current concern to create on-the-job training programs for day care center educators, we have studied eight municipal day care centers in

O projeto de pesquisa que originou este artigo foi financiado pela Fundação de Amparo à Pesquisa do Estado de São Paulo - Fapesp -, mediante concessão de bolsa de mestrado. 
Botucatu, a town in São Paulo State. Our objective was getting to know educators' work and education conditions based on data that allow assessing the initial and continued education procedures applied to them, underlying concepts in their professional practice, their expectations about (the) on-the-job training programs, and the effective needs such programs must meet in view of the quality parameters set up for children education. From the results obtained, we have drawn a panorama and offered suggestions that may help formulate an initial and continued education proposal by drawing from some contributions of historical and cultural theories enriched by critical and recent reflections on the area, as opposed to proposals supported in official documents in force and publicized countrywide.

DAYNURSERIES - VOCATIONAL TRAINING - BOTUCATU-SP_PREPRIMARYTEACHERS

\section{SITUANDO O PROBLEMA}

A partir da Constituição Federal de 1988, que situa a creche como direito da criança, opção da família e dever do Estado, emerge uma preocupação com a qualidade do atendimento, prestado às crianças e famílias da creche, para a promoção da cidadania (Oliveira, 200 I).

Desde a criação do Departamento da Criança no Brasil, em 1919 , e, mais tarde, do Departamento Nacional da Criança - DNCr -, em 1940, houve uma preocupação com a produção e divulgação dos conhecimentos produzidos na área. No entanto, este tipo de discussão permaneceu quase que restrito à esfera médica, dos sanitaristas e higienistas (Kramer, 1995; Vieira, 1988).

Nos seus quase trinta anos de existência, o Departamento Nacional da Criança postulava a educação pré-escolar como uma extensão do lar. A figura da educadora da escola maternal (dois a três anos) e do jardim-de-infância (quatro a seis anos) tinha a função de educar e não de instruir, zelando pela saúde da criança, providenciando alimentação e repouso adequados, cooperando e observando a criança nas suas descobertas etc.

Para a formação dessas educadoras, apontava-se como solução a organização de cursos regulares nas escolas normais ou nos institutos de educação, sendo que a Lei Orgânica do Ensino Normal incluía, nos cursos de especialização, o de educação pré-primária. Além disso, deveriam ser promovidas palestras, visitas a instituições de educação pré-escolar, organizar estágios e cursos intensivos (Vieira, 1988).

No entanto, a concepção subjacente a esse e a outros programas de formação que se seguiram como, por exemplo, o do Projeto Casulo, implementado pela Legião Brasileira de Assistência - LBA -, pautou-se em ampliar ao máximo o atendimento da criança pequena com um custo mínimo e uma par- 
ticipação equivocada da comunidade, o que certamente prejudicou discussões e ações efetivas para a profissionalização.

Atualmente, multiplicam-se estudos voltados à preparação dos profissionais de creche na perspectiva de adequá-los à nova realidade (Inoue, Wajskop, Carvalho, 1998; Kishimoto, 1988, 1998). Qualidades como "ser mãe", "gostar de criança", "ser mulher" etc. cedem lugar a propostas mais elaboradas de profissionalização que objetivam instrumentalizar o educador para desenvolver nas crianças aspectos cognitivos, afetivos e sociais, mediante a proposição de ações e atividades problematizadoras e integradas a outros profissionais, voltadas à faixa etária em questão e que busquem ampliar o universo sociocultural da clientela atendida (Bragagnolo, 1998; Guimarães, 1998; Pantoni, Rossetti-Ferreira, 1998; Paulilo, 1998; Scarpa, 1998).

Somam-se a esse panorama as novas exigências da Lei de Diretrizes e Bases da Educação Nacional - LDB (Saviani, 2000), que uniformiza a nomenclatura dos educadores (anteriormente bastante variada e inespecífica), agora denominados "professores", e estabelece que, ao final da "década da educação", todos os profissionais de educação básica (incluindo os da educação infantil) terão de ser habilitados em nível superior ou formados por treinamento em serviço (art. 61, 87).

Assim, há que se pensar em mecanismos que garantam uma formação continuada de qualidade baseada nas reais necessidades, deficiências e aspirações dos educadores como seres também em desenvolvimento e que trazem consigo uma história pessoal e institucional, marcada por experiências e saberes importantes como ponto de partida na construção de novos conhecimentos e concepções.

A LDB, de 1996 (Saviani, 2000) e os Referenciais para Formação de Professores (Brasil, 1999b) estabelecem o aperfeiçoamento continuado dos profissionais da educação, incluindo aqueles que se dedicam à educação infantil.

Diante dessa nova realidade, há que se garantir essa condição aos funcionários das instituições de educação infantil (creches e pré-escolas), visto que o poder público, por meio de seu sistema municipal de educação e como responsável pela educação infantil no município, tem a incumbência de autorizar, credenciar, supervisionar e fiscalizar as instituições a ele vinculadas - art. I I, inc.IV (Saviani, 2000). Estão previstas na lei, também, a articulação entre os níveis federal, estadual e municipal, bem como a delimitação expressa do montante de recursos a serem aplicados no setor e seu direcionamento privi- 
legiado (art. 8-10). Os municípios também podem optar por integrar os sistemas estaduais de educação ou compor, juntamente com o respectivo estado, uma rede única de educação básica - art. I I, inc.V (Machado, 1998).

No plano técnico, a reordenação dos sistemas impõe tarefas específicas para membros dos conselhos estaduais e municipais de educação, das secretarias de educação, das delegacias de ensino, e, enfim, para todos os responsáveis direta ou indiretamente envolvidos no funcionamento das instituições propriamente ditas. No processo de implementação das disposições legais (Saviani, 2000), um dos principais desafios é o de captar a dimensão educativa prevista para a faixa etária de zero a seis anos, e propor sua respectiva tradução para as atividades do cotidiano das instituições, visto que o texto da LDB traz indicações direcionadas a todos os níveis de ensino incluídos nos sistemas e também determinações específicas para a educação das crianças pequenas (Machado, 1998).

Assim, torna-se necessário implementar um programa de qualificação profissional integrado e direcionado às necessidades e características específicas de cada realidade, articulado com parâmetros comuns que garantam um padrão aceitável de qualidade, definidos nacionalmente.

O Referencial Curricular Nacional de Educação Infantil (Brasil, 1998) reitera a necessidade de ações educacionais, orientadas para a profissionalização, que aliem a escolaridade mínima exigida ( $2^{\circ}$ grau em nível de magistério) à formação permanente em serviço. Também, os Critérios para um Atendimento em Creches que Respeite os Direitos Fundamentais das Crianças (Campos, Rosemberg, 1995), as Diretrizes Curriculares para a Educação Infantil (Lerrer, 1999), as Resoluções CEB n. I/2 (Brasil, 1999, 1999a) e os Subsídios para Credenciamento e Funcionamento de Instituições de Educação Infantil (Neto et al., 1998, 1998a) estabelecem parâmetros de qualidade e condições dignas de atendimento à criança pequena, que supõem uma ação mais consciente e comprometida ética e politicamente, e passam pela qualificação profissional dos educadores em questão.

Recentemente sancionado pela Presidência da República, o Plano Nacional de Educação (Brasil, 200 I), estabelece o prazo máximo de três anos para que os municípios ponham em execução um programa de formação em serviço, em articulação com instituições de ensino superior e com a colaboração técnica e financeira da União e dos estados, visando à atualização permanente e o aprofundamento de conhecimentos dos profissionais que atuam na educação infantil. Note-se que esse tipo de programa não exclui o de formação inicial (escolaridade formal com formação específica definida), mas o complementa. 
No entanto, a gestão democrática do ensino, amplamente defendida e propalada oficialmente, supõe uma participação efetiva e coletiva dos interlocutores envolvidos nesse processo, como ponto de partida para a consecução de ações governamentais mais amplas.

Dado o exposto, e em consonância com outros levantamentos de mesmo teor, buscamos obter subsídios que orientassem uma proposta de formação continuada para professores leigos em creche, com base no estudo de oito unidades municipais na cidade de Botucatu. Neste estudo, cujos dados foram coletados no período de agosto de 1999 a fevereiro de 200 I, nos valemos de consultas a documentos oficiais e institucionais, aplicação de questionários, realização de entrevistas e observações na tentativa de traçar um panorama amplo e contextualizado do histórico de formação desses profissionais até então, o que incluiu conhecer as atuais condições de trabalho e de aprimoramento profissional em serviço.

\section{ESBOÇO CRÍTICO DE UM QUADRO DESOLADOR}

As atendentes participantes de nosso estudo (todas mulheres) situavamse, na sua maioria (84\%) na faixa etária de 26 a 50 anos. Nascidas em Botucatu ou em outras cidades próximas (86\%), eram casadas (54\%), com filhos fora da faixa etária atendida pela creche (82\%) e trabalharam, antes de ingressar na prefeitura, no setor terciário (86\%, especialmente no comércio). Apresentavam grande variação no que se refere ao tempo de trabalho como atendente de creche (desde meses até mais de dez anos) e, especificamente, na creche atual.

No que se refere à situação funcional, a grande maioria das atendentes de creche (86\%) percebiam, à época do estudo, vencimentos líquidos (excetuadas as contribuições da previdência e sindicais) de 2 a 3,5 salários mínimos por uma jornada semanal de 44 horas de trabalho, de segunda a sexta-feira, o que equivale a uma jornada diária de $8 \mathrm{~h}$ e 48 minutos.

Embora a escolaridade exigida para o exercício do cargo/função das atuais atendentes de creche fosse a de $4^{\text {a }}$ série do $1{ }^{\circ}$ grau, todas as participantes possuíam maior escolaridade, sendo que $51 \%$ tinham, pelo menos, o ensino médio completo e, dessas, 35\% possuíam a escolaridade exigida pela legislação em vigor (Campos, 1994; Neto et al., 1998; Saviani, 2000). Mais uma pequena porcentagem ( $10 \%$ ) estava completando a referida escolaridade por conta própria (em escolas particulares, no período noturno). 
Ainda que o Referencial Curricular de Educação Infantil (Brasil, 1998) e os Referenciais para Formação de Professores utilizem, em consonância com a LDB de 1996, a denominação "professor de educação infantil", para designar todos os profissionais responsáveis pela educação direta das crianças de zero a seis anos, tenham eles uma formação especializada ou não, havia, à época do estudo, uma clara distinção entre "professores" e "atendentes" de creche.

Para a Prefeitura Municipal de Botucatu, "professor", na área de educação infantil, era definido como o profissional designado para a pré-escola (quatro a seis anos), que atendia crianças em período parcial (manhã ou tarde) e recebia, à época do estudo, vencimentos de 3,5 salários mínimos (em média) por uma jornada semanal de 24 horas, tendo asseguradas 4 horas semanais para planejamento e/ ou atividades relativas à docência (as chamadas horas de trabalho pedagógico conjunto - HTPCs -, e as horas de trabalho pedagógico livre - HTPLs). Além disso, tinham assegurados 45 dias de férias anuais mais os períodos de recesso escolar, conforme Resolução n.3 da CEB (Brasil, 1997) e planos de carreira e remuneração compatíveis com a qualificação mínima exigida para o exercício da docência (ensino médio completo, na modalidade normal, antigo magistério).

Já o cargo de atendente de creche, responsável pela educação de crianças de quatro meses a seis anos (contrariando a própria LDB, que prevê o atendimento em creches de zero aos três anos de idade) possuía condições bastante adversas em termos de jornada de trabalho, vencimentos, período de férias e plano de carreira, entre outros. Não havia férias coletivas ou períodos de recesso para essas profissionais, nem momentos garantidos dentro da carga horária para estudo e/ou planejamento das atividades a serem desenvolvidas com as crianças, como prevêm, por exemplo, a atual LDB e as resoluções n.2 e 3 da CEB/CNE.

Diante desse quadro, as atendentes de creche ressentiam-se e se queixavam bastante, como pudemos constatar nas respostas e comentários extras obtidos nos questionários, entrevistas e em conversas informais mantidas com as participantes.

Afora condições objetivas de trabalho, explicitadas inclusive por documentos da Prefeitura Municipal de Botucatu a que tivemos acesso, as atendentes estavam sujeitas a ordenações da direção da creche (aprovados e estimulados pela Secretaria Municipal de Educação) que contrariavam orientações de cunho nacional e acadêmico a esse respeito: 
I. número excessivo de crianças por turma: média de dez crianças por atendente, na faixa etária de quatro meses a dois anos; 13 crianças por atendente, na faixa etária de dois a três anos; 20 crianças por atendente, na faixa etária de três a quatro anos; 23 crianças por atendente, na faixa etária de quatro a cinco anos; 25 crianças por atendente, na faixa etária de cinco a seis anos. Esses números comprometem diretrizes recomendadas por Campos e Rosemberg (1995) e Neto et al. (1998a) e excedem em muito ao proposto por Oliveira (200I)';

2. agrupamento de turmas e/ou redivisão de crianças de determinada turma por ocasião de ausências (previstas ou eventuais) de outras atendentes do equipamento;

3. "rodízio de turmas": prática usual em que as atendentes se revezavam periodicamente no atendimento às crianças de diversas faixas etárias sob a alegação da direção de que "todos [crianças e atendentes] devem se acostumar com todos na creche" e "cada atendente deve ter prática e conhecimento de todas as faixas etárias". Isso pode ser evidenciado pelas observações e por respostas obtidas nos questionários e entrevistas, em que a maioria das atendentes afirmou ter passado por, pelo menos, quatro faixas etárias diferentes numa mesma creche num período inferior a dois anos;

4. desvio de função para outros setores da creche, como limpeza, cozinha, substituição de professoras e da direção, manutenção do prédio da pré-escola, confecção de roupas, entre outros. Das participantes, $65 \%$ afirmaram ter sido deslocadas temporariamente de função por várias vezes. Essas práticas contrariavam parâmetros de qualidade de atendimento à criança, estabelecidos nacionalmente e expostos em documentos (Campos, Rosemberg, 1995; Lerrer, 1999; Brasil, 1999; Campos, 1994; Kramer, 1994; Brasil, 1998; Neto et al., 1998, 1998a).

Especialmente nas observações realizadas, notamos também uma diferença gritante em relação à infra-estrutura (materiais, espaço físico, relação

I. Recomenda-se um educador para cada grupo de: cinco a seis crianças (de quatro meses a um ano e dois meses); seis a oito crianças (de um ano e três meses a um ano e oito meses); oito a dez crianças (de um ano e nove meses a dois anos e seis meses); 12 a 15 crianças (de dois anos e sete meses a três anos e seis meses); I5- 17 crianças (de três anos e sete meses a quatro anos e seis meses); 18 a 20 crianças (de quatro anos e sete meses a seis anos). 
adulto/criança etc.) nas creches: as unidades localizadas em bairros de melhor poder aquisitivo e/ou próximas ao centro da cidade apresentavam, sensivelmente, melhores condições de atendimento, e vice-versa. Tivemos a oportunidade de presenciar, por vários momentos (especialmente nas creches localizadas em bairros periféricos), várias crianças fazendo as refeições no chão (todas as turmas ao mesmo tempo), adultos almoçando conjuntamente com as crianças (sem horário de almoço previsto) no refeitório ou em sala, com uma rotina visivelmente caótica ou, quando muito, organizada em razão dos adultos. Mesmo os cuidados físicos às crianças não tinham uma constância e ocorriam de forma intermitente, não prevista na rotina, exceto nas turmas de berçário, onde os procedimentos de higiene e de alimentação dos bebês ocupavam praticamente todo o tempo.

Todas essas constatações desnudam uma rotina não pensada, planeja$\mathrm{da}$, mas que parece ter-se cristalizado e automatizado ao longo do tempo, como uma sucessão de ações sem sentido, que se tornaram hábitos, justificados pelo simples fato de "ter sido sempre assim" (Barbosa, 2000). É como se a rotina fosse um mero acessório, somente percebido e acionado "no varejo" (expressão usada pelas próprias participantes), quando surgiam problemas imediatos: crianças chorando incessantemente quando começavam a freqüentar a creche; problemas (brigas/gritos das crianças, destruição de materiais e brinquedos etc.) advindos da ausência prolongada da educadora da turma para ir ao banheiro, fumar, conversar com outras funcionárias; questões de "mau comportamento" das crianças, famílias e funcionários, entre outras. Nesses casos, a diretora e/ou a equipe técnica eram chamadas para acalmar e "resolver" temporariamente uma situação (como se fosse desvinculada do contexto), abandonando sua função prevalentemente burocrática e administrativa. Houve várias tentativas desse tipo de abordagem com a própria pesquisadora, especialmente quando da ausência da diretora da creche.

É interessante notar a falsa dicotomia, relatada nas entrevistas, existente entre "a professora que ensina" e "a atendente que cuida". As funções de educação apareciam na fala da direção e das próprias atendentes, na maioria das vezes, como a formação e o inculcamento de hábitos de higiene, alimentação e religiosos.

No que se refere especificamente à formação continuada das educadoras, respostas obtidas nos questionários e depoimentos pessoais (inclusive da própria direção e equipe técnica) apontaram uma situação bastante alarmante: nos dois anos anteriores à nossa pesquisa, as atendentes de creche haviam 
tido acesso a, no máximo, quatro ou cinco cursos; não existia acompanhamento e/ou supervisão por parte da equipe técnica em relação ao trabalho das educadoras; não havia, também, um projeto ou mesmo proposta de formação continuada para esses profissionais integrados ao da pré-escola.

Quanto aos cursos/palestras oferecidos pela prefeitura, as participantes relataram uma nítida disparidade entre as oportunidades de acesso das professoras em comparação às atendentes, isto porque as últimas tinham de se revezar nos vários períodos/etapas em que o evento era oferecido "para não atrapalhar a rotina e o funcionamento da creche", ao contrário das primeiras, que tinham esse direito assegurado e previsto no próprio calendário escolar. Além disso, os cursos/palestras eram, na sua maioria, custeados parcialmente pelas próprias participantes, o que prejudicava sobremaneira as atendentes, com menor poder aquisitivo. Muitos dos cursos não contavam "pontos na carreira" para ascensão horizontal das educadoras de creche por serem oferecidos exclusivamente às professoras. Por último, informações extra-oficiais (em caráter sigiloso) davam conta de que a seleção dos palestrantes/cursos a serem contratados ocorria muito mais em razão interesses pessoais (ligações de amizade, parentesco e/ou político-partidárias) dos dirigentes do que voltadas a um projeto intencional de qualificação das educadoras.

$\bigcirc$ acesso aos materiais produzidos, cursos e treinamentos ministrados, assim como os diversos depoimentos obtidos, apontaram para temas e diretrizes teóricas completamente díspares e/ou desvinculadas: eventos de orientação psicomotora conviviam com outros de cunho construtivista; a área de saúde era trabalhada nos seus mais diversos aspectos (de forma não articulada) por profissionais de orientação bastante diferente; cursos variados eram oferecidos por profissionais sem experiência com o trabalho em creche, outros fugiam às especificidades de um trabalho plausível com crianças e a maioria não tinha continuidade nem estava inserida num projeto de formação mais amplo e coeso.

Os documentos produzidos pela Prefeitura Municipal de Botucatu, que tratavam especificamente da área de educação infantil, não estavam em consonância com as exigências de escolaridade, equiparação de salários e condições de trabalho entre professoras e atendentes, expostas nas resoluções n. I 2/99 e 3/97 da CEB. A Lei Municipal n.3.987/99, por exemplo, alterou a exigência de escolaridade de $4^{a}$ série para a de ensino fundamental completo, no que se refere às educadoras de creche (zero a três anos), mantendo a exigida 
pela LDB somente para as professoras (quatro a seis anos). Além disso, não mencionavam a melhoria de condições de trabalho, remuneração e aprimoramento em serviço das atendentes de creche, nem um plano de diretrizes e metas a serem seguidas para a complementação da escolaridade e a implementação de cursos específicos de formação (Kramer, 1994; Neto et al., 1998). A legislação municipal, portanto, mantinha a dicotomia de papéis e de formação entre professoras e atendentes, como se fossem funções díspares e desvinculadas, omitindo-se na necessidade de formulação de políticas integradas de aprimoramento profissional e de atuação.

Na prática, quando se fazia referência à educação infantil no município, nos seus vários aspectos (planejamento, faixa etária atendida, profissionais envolvidos etc.), os participantes se remetiam somente à pré-escola (quatro a seis anos), numa perspectiva de conteúdos e ações francamente escolarizantes, visando ao preparo dessas crianças para o ingresso no ensino fundamental.

Em contrapartida, a maioria das atendentes de creche parecia se adaptar a esse quadro, assimilando a dicotomia cuidado-educação na sua prática diária, como pode ser evidenciado pelo orgulho que várias delas demonstravam de serem "polivalentes" e "prestativas" na creche, já que a higiene e a arrumação do ambiente e das crianças pareciam ter prioridade, encontrando-se desvinculadas de uma proposta pedagógica mais ampla.

Especialmente nas observações realizadas, a preocupação da maioria das atendentes parecia ser a de "passar o tempo", especialmente colocando as crianças para assistir TV ou sentadas a fim de esperar o horário da próxima "atividade". Aumentavam assim o "tempo de espera" das crianças e, quando muito, formavam hábitos ou reproduziam fórmulas escolares tradicionalmente repetitivas e maçantes, ou realizavam treinamentos psicomotores e fonoaudiológicos com as crianças, provavelmente absorvidos nos cursos a que tiveram acesso. Nesse caso, o foco de atenção ficava totalmente centrado no educador, que tomava a iniciativa, propunha os exercícios/jogos e esperava condutas padronizadas das crianças, julgando o que estava "certo" e o que estava "errado", conforme o caso. Noutros casos, o quadro que se delineava era de displicência e abandono no trato com as crianças, em que a atendente demonstrava total desinteresse e desmotivação pelo trabalho, abdicando completamente de seu papel de educadora.

Numa segunda etapa da pesquisa, nos propusemos, à semelhança de Geis (1993), Gomide (1992) e Loch (1986), a proceder a uma caracterização 
mais pormenorizada das concepções e expectativas das atendentes de creche sobre seu trabalho, contrapondo-as com sua prática efetiva com as crianças.

Considerando cada participante da creche como um sujeito potencialmente ativo na construção social desse equipamento e, ao mesmo tempo, do movimento social em que ela se insere, o estudo do cotidiano da creche tem uma importância fundamental para trazer os elementos que possibilitem o conhecimento e a compreensão de seu funcionamento (Geis, 1993).

Assim, enquanto a maioria das atendentes conceituava a creche como "um local seguro onde as mães deixam seus filhos para poderem ir trabalhar" (Geis, 1993; Kuhlmann Jr., 1998) e a criança como um ser "desprotegido", "ingênuo", que necessita de "afeto e atenção", as observações desnudaram o que Kuhlmann Jr. (2000) designa como "pedagogia da submissão": a educação assistencialista marcada pela arrogância que humilha para depois oferecer o atendimento como dádiva, como favor aos poucos selecionados para recebê-lo. Esse autor discute os propósitos e as estratégias da educação assistencialista, que compreende uma pedagogia "pobre para os pobres" e se assenta na inculcação de bons hábitos e boas maneiras, preocupação com a integridade física da criança, à semelhança do encontrado por nós nas entrevistas e observações.

No que diz respeito à ação e função da creche, constatamos, como Geis (1993) e Loch (1986), a ênfase nas atividades de alimentação e a inculcação de valores, como "obediência", "respeito pelas tias", "gratidão", manifesta por forte componente religioso subsidiador das práticas, permeados pela exigência constante de silêncio e imobilidade total das crianças. Concordamos com essas autoras quando apontam para a indefinição do papel desempenhado pelas educadoras, que se traduz em fortes sentimentos de insegurança e insatisfação, já que o discurso e a prática das atendentes participantes de nosso estudo apontavam para funções e papéis oscilantes, que ora se expressavam pelo "tomar conta", ora eram vistos como substitutos e mais capazes que o papel da mãe, ora como mais completos e importantes que o papel da professora: "ela só ensina, mas não cuida".

Fleury (2000), utilizando o conceito de representação social ${ }^{2}$ proposto por Moscovici, situa-o como um corpus organizado de conhecimentos prove-

2. Entendido como o conjunto de crenças, opiniões, significados e informações que se processam num nível simbólico e que permitem tornar inteligíveis aos homens um determinado objeto de sua realidade social. 
niente de um dado momento histórico-social, em que o modo de produção da sociedade determina o modo de pensar e agir dos indivíduos. Nesse sentido, afirma que os professores tendem a levar para sua prática educativa estereótipos de criança que os fazem agir de uma forma alienada, acrítica e mecânica, numa clara transposição das condições de produção e de trabalho a que são submetidos.

Em sua pesquisa com professoras de pré-escola, Fleury constata que, paralelamente a representações e constructos idealizados dessas profissionais sobre o "ser criança", em que esta é considerada um ser inocente, meigo e puro, convive uma prática que privilegia atitudes pedagogizantes, normativas e moralistas que legitimam uma conduta discriminatória para com as crianças de famílias de baixa renda. A autora argumenta que esse caráter aparentemente contraditório permite ao educador projetar inconscientemente suas aspirações e desejos idealizados, que contribuem para uma representação mitificada da infância, ao mesmo tempo em que facilitam a aceitação de um certo sentimento de impotência diante das condições concretas de sua atuação.

Como já assinalado, a comparação com as professoras de pré-escola era inevitável por parte das atendentes, que demonstravam fortes ressentimentos em relação às primeiras: salários bastante diferenciados dos das professoras (em média, aproximadamente o dobro pela metade da carga horária semanal), além de condições bastante díspares em termos de reconhecimento social e condições de formação (inicial e continuada).

Esses ressentimentos eram também traduzidos no discurso das participantes quando afirmavam aprender a trabalhar com crianças no "ensaio-e-erro" ou observando outras colegas na função, além do desrespeito sentido pelos superiores em relação ao seu trabalho, como quando participavam do rodízio e/ou agrupamento de turmas, tendo sob sua responsabilidade um número elevado de crianças. Eram então cobradas excessivamente pela direção e equipe técnica sem a necessária contrapartida e respaldo profissional, deslocadas de função, depreciadas no trabalho etc. Tais aspectos são relatados por Geis ( 1993 ) e Machado ( 1998) e relacionados com o desinteresse e desmotivação pelo trabalho, como também com a indefinição da identidade social vivida pelas educadoras, que ora são requisitadas para exercerem os papéis sociais tradicionalmente atribuídos à mulher, ora são solicitadas enquanto educadoras e profissionais.

Campos et al. ( 1984), tentando traçar um perfil profissional das atendentes de creche a partir do discurso dessas educadoras, apontam para três 
fatores indicadores de "prestígio" na instituição, semelhantes aos por nós encontrados:

I. atividade direta com o educando (quanto mais diretamente ligada ao educando, menor o prestígio do profissional);

2. idade do educando (quanto menor o educando, menor o prestígio do profissional);

3. proximidade do corpo (quanto mais imediatamente ligado à sobrevivência - e, portanto, ao corpo - do educando, menor o prestígio do profissional).

A questão do reconhecimento profissional em creche ainda guarda resquícios de um trabalho leigo, "voluntário", mais dependente do idealismo e boa vontade dos envolvidos do que de uma formação profissional específica. Essa conotação, por sua vez, é repassada para o pessoal empregado nas instituições, fazendo com que possíveis reivindicações por melhoria de salários e condições de trabalho ganhem um caráter negativo, na medida em que se contrapõem à imagem de caridade e de favor, associada ao tipo de atendimento oferecido à população mais pobre (Campos et al., 1984).

No contexto pesquisado, as tentativas de aprimoramento profissional acabavam sendo voltadas às faixas etárias maiores, campo em que o poder público municipal parecia transitar com maior facilidade. Assim, a maioria dos eventos oferecidos (escassos) eram francamente voltados às professoras da préescola e à faixa etária por ela atendida; o planejamento pedagógico e a orientação técnica seguiam caminho idêntico, ambos tendo de ser adaptados às crianças menores de acordo com o bom senso (ou não) de cada educadora, que recebia somente o material por escrito sem a devida discussão e/ou acompanhamento técnico. A participação em eventos ficava restrita ao poder aquisitivo de cada atendente, já que eram parcialmente pagos por esta e a critério da direção da creche que, por sua vez, via-se obrigada a estabelecer um revezamento de educadoras para não atrapalhar a rotina nem proceder à dispensa de crianças, já que não existiam espaços institucionais reservados para esse fim, ou os eventos eram oferecidos fora do expediente de trabalho.

Não é à toa que as entrevistadas afirmaram que um trabalho de formação continuada necessitaria ser voltado à faixa etária de atuação, de teor mais "prático" e específico, com o devido suporte técnico e iniciado no processo de 
seleção, mais rigoroso e específico, com exigência da escolaridade mínima de "segundo grau completo com magistério", passando por um estágio profissionalizante inicial, à semelhança do encontrado por Geis (1993) e Gomide (1992).

As próprias participantes, no entanto, pareciam ter introjetado um modelo escolarizante de educação, privilegiando o desenvolvimento de aspectos escolares tradicionais e a preparação para a alfabetização, entendidos como necessários às crianças maiores de três e/ou quatro anos. Essa transposição do modelo escolar para a creche, além de diminuir a importância da dimensão afetiva e de cuidados ligados ao corpo (Carvalho, 1999), acaba por minimizar a preocupação com o atendimento às crianças menores, famílias e comunidade (Campos et al., 1984), tal como encontramos nas entrevistas e observações.

Nessa perspectiva, Carvalho (1999) situa a psicologização e a feminilização das práticas educacionais que associam o "cuidado" ao universo privado, familiar, e a "docência" à maternagem, à doação incondicional, o que contribui para desqualificá-la como profissão e impedindo um projeto de formação coletivo e propõe a revisão dessas duas categorias nas práticas de formação dos educadores numa perspectiva profissional e histórica. Para a autora, o "cuidado" pode, sim, constituir um aspecto privilegiado que inclua a afetividade como parte integrante do trabalho pedagógico.

Kuhlmann Jr. (1998, 2000a) aponta para a polarização entre o assistencial e o educacional, que opõe a função de guarda e proteção à função educativa, como se elas fossem incompatíveis, excludentes. Tal concepção, segundo o autor, colabora para que os cuidados e a assistência sejam deixados de lado, secundarizados, e o "educacional" (leia-se, "escolarizante") seja elevado à categoria de "atividade nobre", mais importante.

Essa polaridade se refletiu na avaliação feita pelas atendentes sobre a escolaridade formal exigida pela legislação, que representava, além de elevar o seu status profissional à categoria de professoras, a possibilidade de elas se desvincularem de atividades tidas como desagradáveis, relacionadas aos cuidados mais próximos com as crianças. No entanto, as educadoras desconfiavam da efetivação da lei, dada a falta de prioridade até aquele momento demonstrada pelo poder público.

Em contrapartida, como bem evidencia Kuhlmann Jr. (1998), a educação infantil não se pode furtar à transmissão de conhecimentos sobre o mundo, sobre a vida. É claro que a educação infantil precisa estabelecer uma articulação com o ensino de primeiro grau. Mas o modelo da "escola primária" é inadequado para 
essa faixa etária - em alguns aspectos, até mesmo para a clientela do ensino fundamental. Em outras palavras, como bem assinala Machado (1998), reivindicar uma formação específica para os profissionais de creche não pode significar, portanto, preparar educadores para copiarem o modelo do ensino fundamental, mas para captarem as especificidades do trabalho com crianças menores.

Paralelamente ao discurso escolarizante, questões básicas e de suma importância permaneciam pendentes e requeriam equacionamento urgente, como as evidenciadas por discursos velados das atendentes. Maus-tratos (físicos e/ou psicológicos) de crianças; discriminação de pessoas (crianças, funcionários, mães); problemas de relacionamento e falta de comunicação com as famílias atendidas; autoritarismo da maioria das diretoras de creche, hierarquia entre atendentes; "pressão" funcional no interior da instituição (para que não se efetuassem mudanças, denúncias, críticas etc.) e entre funcionárias e destas com a direção da creche e/ou outras instâncias; omissão de dirigentes e equipe técnica; inadequação/desequilíbrio psicológico de várias educadoras, que se refletiam especialmente no trato com as crianças. Esses aspectos também foram encontrados por Geis (1993) e Loch (1986) e apontados como constituintes de um quadro institucional perverso que precisa ser levado em conta na consecução de um projeto de formação que se pretende mais realístico e abrangente.

Duarte (1999) e Mello (2000) complementam e enriquecem essa discussão, propondo que o educador ultrapasse a mera "consciência-em-si" alienada, espontânea e naturalmente dada, perene, não intencional - rumo a um novo patamar, o da "consciência-para-si" - superação do caráter espontâneo e natural, relação consciente do indivíduo para com as condições particulares de sua existência e de suas múltiplas determinações. Desse modo ele poderá se posicionar de forma crítica e consciente diante do processo de alienação e expropriação a que é constantemente submetido e desenvolver ao máximo não só suas possibilidades dentro da prática educativa, mas também se desenvolver como indivíduo.

Davidov ( 1995) aponta que uma das tarefas essenciais do educador crítico e consciente consiste em perceber as possibilidades de humanização de sua atividade que the permitam promover o desenvolvimento e o nível de consciência e de autonomia de seus educandos, estabelecendo assim um novo patamar de compreensão do papel da educação no processo de desenvolvimento humano. Isso só é possível a partir dessa relação consciente do educador com seu próprio condicionamento, com o conhecimento da realidade, com 
os procedimentos e técnicas, com a linguagem, com os usos e costumes, com os outros homens, com sua vida e consigo mesmo, um posicionamento marcado pela intencionalidade (Mello, 2000).

Vigotsky ( 1 997) faz a distinção entre "conceitos cotidianos" e "conceitos científicos". Os primeiros incorporam-se à experiência do sujeito de forma direta, espontânea, prática, empírica, podendo implicar generalizações arbitrárias que não ultrapassam o nível dos pseudoconceitos, ou seja, não envolvem a sistematização nem um caráter consciente do processo. Os "conceitos científicos" implicam a superação da relação imediata entre o objeto e o conceito, no estabelecimento de inter-relações e generalizações, exigindo um nível de abstração e uma atividade intelectual que lhe conferem um caráter mais consciente e sistemático e, portanto, intencional.

Mello (2000) destaca a importância da incorporação dos conceitos científicos em um projeto de formação de educadores. Para a autora, no entanto, é necessário atentar para os riscos do verbalismo e do distanciamento da realidade concreta. Nesse sentido, propõe uma interlocução com a atividade prática, real, num constante movimento de ir-e-vir que permita a fixação dos conceitos de uma forma dinâmica, integrada, que promova um processo de desenvolvimento e aperfeiçoamento permanente dos educadores - o pensamento conceitual autêntico.

Por esse prisma, um projeto continuado de formação de professores torna-se amplo e complexo. Um educador sensível, consciente de seu papel, intencionalmente engajado em promover o desenvolvimento e o bem-estar das crianças sob sua responsabilidade, necessita de condições infra-estruturais (materiais, pessoais, físicas) para que isso se efetive (Campos, Rosemberg, 1995; Neto et al., 1998).

Fleury (2000) propõe um projeto de formação continuada que vá além do domínio de técnicas, conteúdos e habilidades; que se proponha a resgatar, "reapresentar" reminiscências da infância junto aos próprios educadores, levando-os a desenvolver um sentimento de empatia e solidariedade com relação à criança e passa, posteriormente ao estudo das representações sociais sobre a infância adquiridas historicamente, capaz de levá-los à maior compreensão e contextualização de seu papel educativo.

Em nosso estudo, constatamos condições de trabalho e de formação das professoras de creche que estão muito aquém de um projeto educacional humanizador, que ultrapasse o imediato, "rotineiro", "naturalmente dado", alie- 
nado, aistórico (Barbosa, 2000). Isso se refletia nas formas de pensar e agir das educadoras em relação às crianças, empobrecendo as possibilidades de interação, desenvolvimento da autonomia, formação de conceitos etc., destituindo o educador de seu papel mediador intencionalmente pensado e construído coletivamente.

Em contrapartida, é importante lembrar que esse quadro estava inserido numa rede de relações institucionais mais amplas em que chefias, equipe de supervisão e poder público municipal, reforçavam concepções e práticas subjacentes pela falta de conhecimento e de clareza dos pilares de um projeto educativo que pudesse vir a modificar esse estado de coisas. Esses dirigentes também pareciam não ter aprofundado suas reflexões acerca do papel da creche e de seus profissionais, já que também atuavam na base do "ensaio-e-erro", sem sequer estabelecer uma interlocução entre si e com o conhecimento produzido até então, agindo de forma amadorística e aparentemente descomprometida politicamente.

Nesse contexto, consideramos que um projeto de formação continuada, que se pretenda mais amplo e realístico, não se pode furtar a propor outras frentes de atuação que permitam torná-lo efetivo.

O documento Referenciais para Formação de Professores aborda formas de promover a profissionalização do magistério em todos os níveis, inclusive o da educação infantil, tendo como princípios a articulação das ações formativas, da avaliação da atuação profissional e da progressão da carreira na perspectiva do desenvolvimento de uma cultura de responsabilidade por parte de todos os envolvidos, ou seja, das secretarias de educação, das agências formadoras e dos professores.

Entretanto, uma análise mais atenta e minuciosa desse documento (Arce, 200 I ) aponta para uma formação instrumental, "prática", que reforça o cunho psicologizante/escolarizante do atendimento infantil. Ele prevê a realização de observações, registros, estágios e a participação dos educadores em grupos de estudo e supervisão, a figura do "professor-formador"3 e a avaliação da atuação profissional para fins de progressão na carreira sem, no entanto, mencionar a garantia de alocação de verbas e investimentos, o incremento das condi-

3. Profissional com larga experiência docente e reconhecido mérito profissional que funciona como "modelo" aos professores iniciantes, oferecendo estágios e colaborando nos momentos de reciclagem e aprimoramento profissional dos educadores, ao mesmo tempo em que auxilia na incrementação das propostas pedagógicas junto aos alunos (Brasil, 1999b). 
ções infra-estruturais (de pessoal e materiais) e as estratégias de formação dos "formadores de professores".

Todas as questões pertinentes ao aperfeiçoamento dos educadores são tratadas nos referenciais a partir de condições ideais, que parecem existir a priori, bastando empenho e boa vontade dos profissionais envolvidos para que sejam postas em prática, numa clara conotação voluntária, doadora (Arce, 200 I).

No caso da educação infantil, em particular, os Referenciais para Formação de Professores (Brasil, 1999b) pressupõem que os educadores de creche têm asseguradas as horas de trabalho pedagógico dentro da jornada de trabaIho, à semelhança dos demais professores, o que constitui sério equívoco. Além disso, o atendimento em período integral e, conseqüentemente, a disparidade de carga horária entre os professores de creche e os demais, não são considerados em sua especificidade, afora outras condições adversas de trabalho e de salário que certamente necessitam ser equacionadas para que não se corra risco do enfraquecimento da categoria, de divisão e competição internas, que podem provocar uma evasão de professores da educação infantil para outros níveis de ensino (Arce, 200 I).

Em nosso estudo, a maioria das atendentes de creche deixou clara a reivindicação de condições mínimas (infra-estruturais) em termos de carga horária, planejamento e supervisão, condições dignas de trabalho e de formação como pressupostos da exeqüibilidade de um projeto de formação continuada e do equacionamento de questões relativas ao atendimento prestado, com o que concordamos prontamente.

Ponderamos questões como as discutidas por Kuhlmann Jr. ( 1998), quando argumenta que a situação das pessoas que trabalham nas creches brasileiras não é algo que se possa pensar em reverter a partir de uma proposta de formação em serviço. Esta poderá resultar em algum benefício consistente e duradouro, caso esteja sendo proporcionada junto com outras medidas, tais como a regularização das condições de trabalho, a valorização salarial e a formação prévia ou inicial, ou ainda quando seja concomitante ao favorecimento da escolarização básica e específica daqueles que estão atuando, iniciativas que envolvem toda uma política para a educação infantil.

Trabalhos sistematizados que resgatem componentes históricos e institucionais e que busquem estabelecer uma interlocução com os agentes envolvidos, tanto no nível do discurso quanto no das práticas e de suas implicações para $\mathrm{O}$ atendimento à criança pequena, podem constituir um ponto de partida 
para a reflexão e a revisão das práticas educacionais por parte dos agentes envolvidos nesse processo.

\section{ALGUMAS ALTERNATIVAS}

Entendemos que, mesmo diante das limitações e disparidades apontadas, é possível efetuar algumas mudanças que contribuam de início para a melhoria das condições de trabalho e de formação das educadoras de creche:

- melhoria das condições infra-estruturais (de material, físicas) mediante um programa de austeridade no uso de verbas públicas e realização de parcerias com entidades privadas, conselhos da criança e prefeituras da região; isso inclui melhoria de salários, plano de carreira, revisão de carga horária e do número de crianças por educador, equiparação às condições de trabalho dos professores, adaptação de prédios e de espaços destinados às crianças etc.;

- seleção de diretores de creche por concurso público que obedeça a critérios técnicos, mediante contratação de profissionais gabaritados na área que não tenham relações de parentesco e/ou amizade com os participantes, e em que as atuais diretoras tenham direito de participar em igualdade de condições com os demais concorrentes;

- incremento do número de equipes técnicas mediante seleção efetuada nos mesmos moldes da anterior, excluindo-se a participação dos atuais técnicos já concursados;

- realização de curso básico inicial que inclua os diversos aspectos referentes ao atendimento em creche permitindo subsidiar técnicos e diretores na elaboração de um projeto pedagógico integrado e coletivo de atuação (saúde e nutrição, relação creche-família, relações interpessoais, gerenciamento, formação continuada, rotina, planejamento psicopedagógico, concepção/histórico de creche, de criança e do atendimento infantil, linhas teóricas atuais na área de educação infantil e suas implicações, entre outros);

- aperfeiçoamento e atualização da legislação municipal que garanta a contratação e o aprimoramento profissional dos educadores de creche, inicialmente de acordo com parâmetros nacionais estabelecidos pela legislação vigente e, posteriormente, buscando ultrapassar esse 
patamar, na medida em que os profissionais adquiram autonomia para uma atuação mais consciente, contextualizada e crítica;

- acompanhamento e supervisão do trabalho realizado em todas as instâncias (dirigentes, equipe técnica, diretores, professores) por profissionais reconhecidamente gabaritados mediante contratações (inicialmente terceirizadas) e parcerias com universidades, centros de pesquisa e de referência na área;

- criação de espaços institucionais (grupos de estudo, bibliotecas para educadores, cursos e treinamentos periódicos, reuniões para planejamento e avaliação, momentos para registro e observação, intercâmbio de profissionais, visitas a outras creches etc.) garantidos dentro da jornada de trabalho, de forma a proporcionar momentos de reflexão e aprimoramento que visem à melhoria do atendimento a crianças e famílias da creche pelo aperfeiçoamento pessoal e profissional de seus educadores.

Esperamos, a partir dessas medidas e de uma real vontade política, contribuir para o início de um processo que considere o educador como sujeito de direitos e passível de qualificação e priorização por parte do poder público. Isso significa reconhecer e estimular permanentemente o papel dos professores como mediadores da cultura e do conhecimento produzido socialmente, que passa, necessariamente, pela formação de um educador reflexivo, consciente de seu papel e de sua inserção no tecido social, engajado histórica e politicamente, capaz de reivindicar e de contribuir ativamente para um projeto educacional integrado e consistente.

\section{REFERÊNCIAS BIBLIOGRÁFICAS}

ARCE, A. Compre o kit neoliberal para a educação infantil e ganhe grátis os dez passos para se tornar um professor reflexivo. Educação \& Sociedade, v. 22, n.74, p. I-21, 200 I.

BARBOSA, M. C. S. Fragmentos sobre a rotinização da infância. Educação \& Realidade, v. 25, n. I, p.93-II3, 2000.

BRAGAGNOLO, A. Um caminho de desafios e descobertas: a formação do profissional de educação infantil. In: CONGRESSO PAULISTA DE EDUCAÇÃO INFANTIL, I. Águas de Lindóia, 1998. Resumos do... São Paulo: Fundação Orsa, 1998. 
Trabalho e formação dos educadores...

BRASIL. Conselho Nacional de Educação. Câmara de Educação Básica. Resolução CEB n. /, de 7/4/99. Institui as diretrizes curriculares nacionais para a educação infantil. Brasília, 1999.

Resolução CEB n.2, de 19/4/99. Institui as diretrizes curriculares nacionais para a formação de docentes da educação infantil e dos anos iniciais do ensino fundamental, em nível médio, na modalidade Normal. Brasília, 1999a.

Resolução CEB n.3, de 8/10/97. Fixa as diretrizes para os novos planos de carreira e de remuneração para o magistério dos estados, do Distrito Federal e dos municípios. Brasília, 1997.

BRASIL. Ministério da Educação e do Desporto. Secretaria de Educação Fundamental. Referencial curricular nacional de educação infantil. Brasília, 1998. v. I .

BRASIL. Presidência da República. Lei n. 10. I72: Plano Nacional de Educação. Diário Oficial da União, Brasília, 10 jan.200I.

BRASIL. Ministério da Educação. Secretaria de Educação Fundamental. Referenciais para formação de professores. Brasília, $1999 \mathrm{~b}$.

CAMPOS, M. M. M. Educar e cuidar: questões sobre o perfil do profissional de educação infantil. In: BRASIL. Ministério de Educação e Cultura. Por uma política de formação do profissional de educação infantil. Brasília, 1994. p.32-42.

CAMPOS, M. M. M.; ROSEMBERG, F. Critérios para um atendimento em creches que respeite os direitos fundamentais das crianças. Brasília: MEC/SEF/Coedi, 1995.

CAMPOS, M. M. M. et al. Profissionais de creche. Cadernos Cedes, v.9, p.39-66, 1984.

CARVALHO, M. P. No coração da sala de aula: gênero e trabalho docente nas séries iniciais. São Paulo: Xamã, 1999.

DAVIDOV, V. V. Influence of L. S. Vygotsky on education: theory, research and practice. Educational Researcher, v.24, n.3, p. I2-21, 1995.

DUARTE, N. A Individualidade para-si: contribuição a uma teoria histórico-social da formação do indivíduo. 2.ed. Campinas: Autores Associados, 1999.

FLEURY, M. das G. Há uma criança dentro da professora? In: OLIVEIRA, Z. de M. R. (org.) Educação infantil: muitos olhares. 4.ed. São Paulo: Cortez, 2000. p. I3 I- I 58.

GEIS, R. M. Criar ou educar crianças? Estudo das representações de mães e de educadores sobre o papel da creche. São Paulo, 1993. Tese (dout.) Instituto de Psicologia da Universidade de São Paulo.

GIL, A. C. Métodos e técnicas de pesquisa social. 5. ed. São Paulo: Atlas, 1999. 
GOMIDE, E. F. de S. Educadores de creche: concepções e prática (um estudo de caso). São Paulo, 1992. Dissert. (mestr.) Faculdade de Educação da Universidade de São Paulo.

GUIMARÃES, C. M. Educador infantil: mudança do paradigma para a sua formação inicial e continuada em serviço. In: CONGRESSO PAULISTA DE EDUCAÇÃO INFANTIL, I . Águas de Lindóia, 1998. Resumos do... São Paulo: Fundação Orsa, 1998.

INOUE, A.; WAJSKOP, G.; CARVALHO, S. P. Referencial curricular nacional de educação infantil. Criança, v.30, p.3-5, 1998.

KISHIMOTO, T. M. Mapeamento da formação de profissionais de educação infantil no Estado de São Paulo, 1998. [Apresentado no I Copedi, 20 a 23 out. 1998, Águas de Lindóia, SP.] [Comunicação oral]

Pré-escola e democratização do ensino. /déias, v.2, p. 19-21, 1988.

KRAMER, S. A Politica do pré-escolar no Brasil: a arte do disfarce. 5.ed. São Paulo: Cortez, 1995. KRAMER, S. Currículo de educação infantil e a formação dos profissionais de creche e préescola: questões teóricas e polêmicas. In: BRASIL. Ministério da Educação e Cultura. Por uma política de formação do profissional de educação infantil. Brasília: SEF, I994. p. I6-3I.

KUHLMANN JR., M. Educação infantil e currículo. In: FARIA, A. L. G.; PALHARES, M. S. (orgs.) Educação infantil pós-LDB: rumos e desafios. 2.ed. Campinas: Autores Associados, 2000. p.5 I-65.

Histórias da educação infantil brasileira. Revista Brasileira de Educação, n. I 4, p.5-18, 2000a.

Infância e educação infantil: uma abordagem histórica. Porto Alegre: Mediação, 1998.

LERRER, D. É de pequeno que se aprende. Educação, v.219, p. 18-21, 1999.

LOCH, G. H. M. Creche: papel das pajens e administradoras: realidade e fantasia. São Paulo, 1986. Dissert. (mestr.) Pontifícia Universidade Católica de São Paulo.

MACHADO, M. L. de A. Formação profissional para educação infantil: subsídios para idealização e implementação de projetos. São Paulo, 1998. Tese (dout.) Pontifícia Universidade Católica de São Paulo.

MELLO, S. A. Linguagem, consciência e alienação: o óbvio como obstáculo ao desenvolvimento da consciência crítica. Marília: Unesp Publ., 2000.

NETO, A. F. et al. Considerações sobre a regulamentação para a formação do professor de educação infantil. In: BRASIL. Ministério da Educação e Cultura. Subsídios para credenciamento e funcionamento de instituições de educação infantil. Brasília: SEF, I 998. v. I , p. I7-24. 
NETO, A. F. et al. Fundamentos legais, princípios e orientações gerais para a educação infantil. In: BRASIL. Ministério da Educação e Cultura. Subsídios para credenciamento e funcionamento de instituições de educação infantil. Brasília: SEF, I 998a. v. I , p.9-I6.

OLIVEIRA, Z. de M. R. et al. Creches: crianças, faz-de-conta \& cia. 9.ed. Petrópolis: Vozes, 2001 .

PANTONI, R. V.; ROSSETTI-FERREIRA, M. C. A Formação continuada do educador: desafios e conquistas. Criança, v.30, p.37-39, 1998.

PAULILO, V. L. A. M. Educação infantil: os direitos das crianças e os deveres dos educadores. In: CONGRESSO PAULISTA DE EDUCAÇÃO INFANTIL, I. Águas de Lindóia, 1998. Resumos do ... São Paulo: Fundação Orsa, 1998.

SAVIANI, D. A Nova lei da educação: trajetória, limites e perspectivas. Campinas: Autores Associados, 2000.

SCARPA, R. Era assim, agora não: uma proposta de formação de professores leigos. São Paulo: Casa do Psicólogo, 1998.

VIEIRA, L. M. F. Mal necessário: creches no Departamento Nacional da Criança ( 1940 - 1970). Cadernos de Pesquisa, n.67, p.3-16, nov. 1988.

VYGOTSKI, L. S. Obras escogidas. el significado histórico de la crisis de la psicologia. 2.ed. Madrid: Visor, 1997. v.l.

Recebido em: dezembro 2002

Aprovado para publicação em: junho 2005 